\title{
Metabolic response to alcohol ingestion in Drosophila hydei
}

\author{
R. Gonzàlez-Duarte and \\ S. Atrian
}

\author{
Department de Genètica, Facultat de Biologia, \\ Universitat de Barcelona, Diagonal, 637-643 \\ 08028 Barcelona, Spain.
}

\begin{abstract}
Adults of Drosophila hydei react differently towards ethanol and propan-2-ol treatment. Ethanol concentration rises progressively in ethanol fed flies and the acetaldehyde produced is quickly metabolised. Alcohol dehydrogenase and aldo-keto reductase activities rise considerably after $\mathbf{4 8}$ hours of ethanol treatment decreasing progressively afterwards. In propan-2-ol treated flies propan-2-ol concentration rises in the first $\mathbf{7 2}$ hours after ingestion and the acetone produced tends to accumulate in the flies but eventually it is excreted. Alcohol dehydrogenase activity decreases markedly whereas aldo-keto reductase activity is induced by three-fold after 72 hours. Cycloheximide treatment inhibits the recovery of alcohol dehydrogenase activity of propan-2-ol treated flies when transferred to normal medium.
\end{abstract}

\section{INTRODUCTION}

Alcohols are usual components found in natural environments of some species of Drosophila (McKechnie and Morgan, 1982). So, the effects of ethanol and propan-2-ol have been studied in $D$. melanogaster (Van Delden, 1982) D. funebris and D. immigrans (Gonzàlez-Duarte and Vilageliu, 1984; Vilageliu and Gonzàlez-Duarte, 1984) $D$. lebanonensis (David et al., 1979) and D. buzzatii (Fontdevila et al., 1980). It is also well known that alcohol dehydrogenase (ADH) plays a crucial role in alcohol metabolism catalysing the conversion of primary and secondary alcohols to aldehydes and ketones. Species differ in their alcohol tolerance and this has been attributed to their ADH activity. The same effect has been described for different alleles at the alcohol dehydrogenase locus in D. melanogaster (Vigue and Johnson, 1973).

But, the amount of information concerning $\mathrm{ADH}$ activity changes in flies reared on ethanol or propan-2-ol contrasts with the lack of information about other enzymes involved in alcohol tolerance and alcohol adaptation in Drosophila. Also, metabolites produced after alcohol oxidation have not been determined and they could shed light on enzyme activities needed to produce them. Concerning other enzymes than $\mathrm{ADH}$, an enzyme activity analogous to a mammalian NADPHdependent aldehyde reductase (AKR) has been reported in Drosophila (Davidson et al., 1978). This enzyme can use acetaldehyde and acetone as substrates and AKR activity is detectable in $D$. melanogaster ADH-null and AO-null and in $D$. hydei wild type flies (Atrian and Gonzàlez-Duarte, 1985). The study of the evolution of both enzyme activities together with the quantification of alcohols and their oxidation products in the flies as well as in the external media could help us understand alcohol metabolism in Drosophila. So, one of the aims of the current study has been to obtain information concerning $\mathrm{ADH}$ and $\mathrm{AKR}$ activities in ethanol and propan-2-ol treated flies and to quantify alcohols and metabolite concentrations after long periods of alcohol treatment.

Another point which deserves interest is the recovery of ADH activity of propan-2-ol treated flies when transferred to normal medium. It has been claimed that acetone produces a temporary decrease of $\mathrm{ADH}$ activity by causing an interconversion of isozyme forms (Papel et al., 1979) but there is no satisfactory explanation at present of the increase in enzyme activity that follows transfer of the flies to non-alcoholic medium. An experiment has been set to test whether the rapid adaptation of propan-2-ol treated flies to an alcohol-free environment is due to re-activation of pre-existing enzyme molecules or new synthesis of enzyme.

\section{MATERIALS AND METHODS}

\section{Materials}

A wild population of $D$. hydei was caught in Menorca in 1973. Wild females of this population 
were used to construct a laboratory strain that has been kept in the laboratory since then.

Ethanol, propan-2-ol, tert-butanol, acetone, sucrose and protamine sulphate were from Merck (Darmstadt, Germany). Acetaldehyde and NADPH were from Fluka (Buchs, Switzerland). $\mathrm{NAD}^{+}$and cycloheximide were from Sigma (London) Chemical Co. (Poole, Dorset, U.K.). All other laboratory reagents were from Merck (Darmstadt, Germany).

\section{Enzyme assays}

ADH activity was quantified according to Juan and Gonzàlez-Duarte (1980). One unit of activity reduces $1 \mu \mathrm{mol}$ of $\mathrm{NAD}^{+} / \mathrm{min}$ at $25^{\circ} \mathrm{C}$. AKR activity was quantified according to Turner and Tipton (1972) with minor modifications. AKR activity was monitored by following the decrease in absorbance at $340 \mathrm{~nm}$. In the standard assay $0.15 \mathrm{ml}$ of NADPH $75 \mu \mathrm{M}$ in buffer and $0.15 \mathrm{ml}$ of acetaldehyde $0.96 \mathrm{M}$ in buffer were added to $0.80 \mathrm{ml}$ of $100 \mathrm{mM}$ sodium phosphate buffer, $p \mathrm{H} 7 \cdot 0$. Coenzyme and substrate solutions were freshly prepared. The reaction was initiated by the addition of $0.10 \mathrm{ml}$ of sample solution and the initial velocity was recorded. One unit of aldo-keto reductase activity oxidises $1 \mu \mathrm{mol}$ of $\mathrm{NADPH} / \mathrm{min}$ at $25^{\circ} \mathrm{C}$.

Enzyme activities were measured using a Cary 219 recording spectrophotometer.

\section{Alcohol treatment}

Groups of 20 adults (3-4 days old) reared at $17^{\circ} \mathrm{C}$ on a killed yeast medium were transferred to airtight $50 \mathrm{ml}$ vials containing $2 \mathrm{ml}$ of an aqueous solution of 3 per cent $(\mathrm{w} / \mathrm{v})$ sucrose and a given concentration of ethanol or propan-2-ol. This solution was absorbed into cotton wadding at the bottom of the vial. Cultures were then kept at $20^{\circ} \mathrm{C}$. Vials were opened at $4^{\circ} \mathrm{C}$ at different times and enzyme activities and alcohol, acetaldehyde and acetone concentration were determined in the flies. All cotton wadding was also immediately transferred to an airtight vial at $4^{\circ} \mathrm{C}$ to quantify these compounds in the external medium by gas-liquid chromatography (g.l.c.).

In another experiment groups of 20 adult flies that had been kept on 1 per cent $(v / v)$ ethanol or 0.5 per cent $(\mathrm{v} / \mathrm{v})$ propan-2-ol for 24 hours as has been described were transferred to airtight $50 \mathrm{ml}$ vials containing $2 \mathrm{ml}$ of 3 per cent $(\mathrm{w} / \mathrm{v})$ aqueous solution of sucrose and 0.5 per cent $(\mathrm{w} / \mathrm{v})$ cycloheximide. This solution was also absorbed into cotton wadding at the bottom of the vial. Control vials had the same number of flies and sucrose solution without cycloheximide.

\section{Preparation of the samples}

To prepare the samples all adults of each vial were weighed and homogenised in $100 \mathrm{mM}$ sodium phosphate buffer, $p \mathrm{H} 7.0$ at $4^{\circ} \mathrm{C}$ using $0.013 \mathrm{ml}$ buffer per $\mathrm{mg}$ of wet weight of flies. Afterwards $0.14 \mathrm{ml}$ of 2 per cent $(\mathrm{w} / \mathrm{v})$ salmine sulphate in buffer were added per $\mathrm{ml}$ of solution and the homogenate was then centrifuged at $12,000 \mathrm{~g}$ for $20 \mathrm{~min}$ at $4^{\circ} \mathrm{C}$. The supernatant was used to determine enzyme activities and for g.l.c. analysis and the pellet was discarded.

\section{Gas chromatography}

A Perkin-Elmer gas chromatograph (SIGMA 3B, SIGMA 15) equipped with flame ionisation detector was used to quantify ethanol, propan-2-ol, acetaldehyde and acetone. Samples were run in a stainless-steel column $(2 \mathrm{~m} \times 3.1 \mathrm{~mm})$ packed with Carbowax-1500. A head space accesory (HS 6) was also used for more precise injection of sample. Sample is introduced at once pressurised by inert gas so that sample manipulation is completely avoided. This type of equipment has been used previously in routine analysis of alcohols in blood (Jentzsch, D. et al., 1967) but up to now has not been reported in Drosophila studies. The conditions of a routine analysis were as follows: headspace unit temperature $60^{\circ} \mathrm{C}$; pressurisation time $4 \mathrm{~min}$; injection temperature, $150^{\circ} \mathrm{C}$. Gas flow was the following: $\mathrm{N}_{2}, 30 \mathrm{ml} / \mathrm{min} ; \mathrm{H}_{2}, 20 \mathrm{ml} / \mathrm{min}$ and air, $25 \mathrm{ml} / \mathrm{min}$. Fig. 1 gives the g.l.c. output of the standards with retention times and relative response factors.

At the times indicated in the experiment all cotton wadding or $0.5 \mathrm{ml}$ of sample solution were transferred to air tight vials. 1 per cent $(\mathrm{v} / \mathrm{v})$ tertbutanol was added as internal standard: $0.2 \mathrm{ml}$ to cotton wadding vials and $0.1 \mathrm{ml}$ to sample solutions. Samples were kept at $-40^{\circ} \mathrm{C}$ until required. All determinations were done at least in triplicate with independent samples.

\section{Experimental conditions for g.l.c. determination and enzyme activities}

Three different vials were set up for each experiment. The first one contained the alcohol-sucrose solution on cotton wadding but had no flies. It served as a control for evaporation and/or spontaneous transformation of the alcohols. The second 


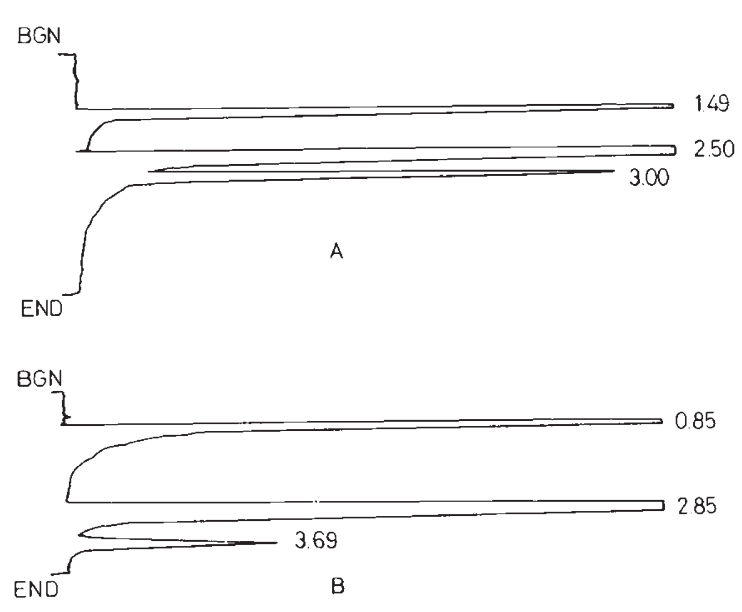

Figure 1 g.l.c. output of the standards and retention times. (A) $15 \mathrm{mM}$ acetone, $t=1.49 ; 25 \mathrm{mM}$ tert-butanol, $t=2.50$ and $15 \mathrm{mM}$ propan-2-ol, $t=3 \cdot 00$. (B) $15 \mathrm{mM}$ acetaldehyde, $t=0.85 ; 25 \mathrm{mM}$ tert-butanol, $t=2.85$ and $15 \mathrm{mM}$ ethanol, $t=3 \cdot 69$. Response factors are for acetaldehyde, $1 \cdot 10$; acetone, 1.42; propan-2-ol, 1.51 and ethanol, 3.36.

vial had $2 \mathrm{ml}$ of 3 per cent $(\mathrm{w} / \mathrm{v})$ aqueous sucrose solution and 20 adults of $D$. hydei. Enzyme activities and ethanol, propan-2-ol, acetaldehyde and acetone concentrations were determined at the times indicated. Finally, the third vial had the same number of adults as the second and contained $2 \mathrm{ml}$ of 3 per cent $(w / v)$ aqueous sucrose solution supplemented with 1 per cent $(\mathrm{v} / \mathrm{v})$ ethanol or 0.5 per cent $(\mathrm{v} / \mathrm{v})$ propan-2-ol.

\section{RESULTS}

\section{Preliminary experiment}

An experiment was done to follow ethanol, propan-2-ol and acetone concentrations by g.l.c. in adults of $D$. hydei fed a sucrose solution containing 1 per cent $(\mathrm{v} / \mathrm{v})$ ethanol or 0.5 per cent $(\mathrm{v} / \mathrm{v})$ propan-2-ol. The relationships between enzyme substrate and product concentration were calculated at 2, 4, 8 and 24 hour. The results are shown in fig. 2 .

\section{$A D H$ and $A K R$ enzyme activities and alcohol concentration in flies treated with ethanol and propan-2-ol}

Another experiment followed ADH and AKR enzyme activities in treated flies for longer periods of time. 1 per cent $(\mathrm{v} / \mathrm{v})$ ethanol and 0.5 per cent $(\mathrm{v} / \mathrm{v})$ propan-2-ol concentration did not affect the viability of the flies during the time of the experiment. Ethanol-acetaldehyde and propan-2-olacetone concentrations were also determined in

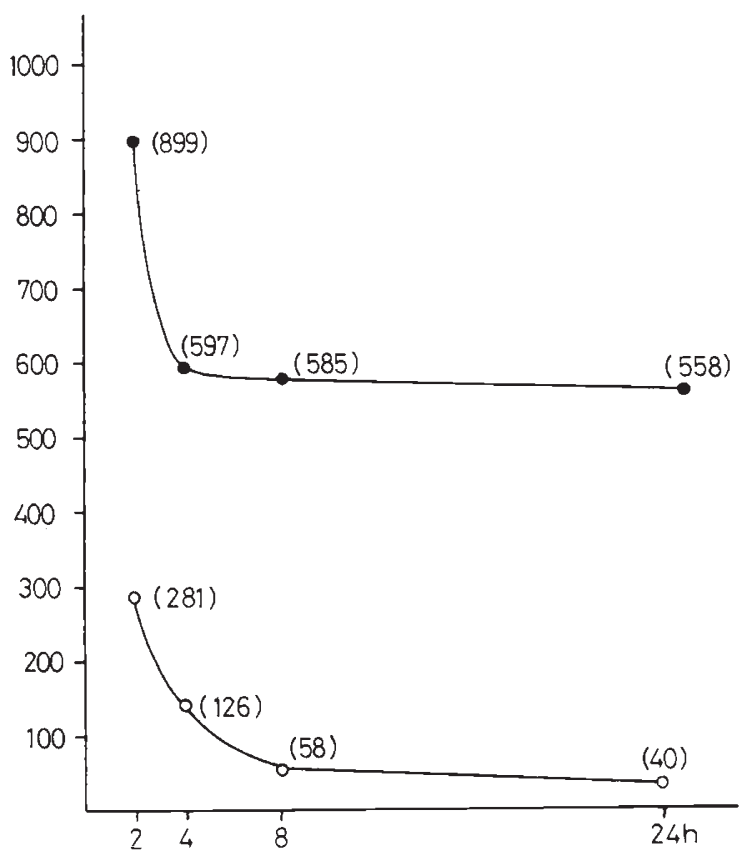

Figure 2 Relationships between enzyme substrate and product concentration in 1 per cent $(\mathrm{v} / \mathrm{v})$ ethanol and 0.5 per cent $(\mathrm{v} / \mathrm{v})$ propan-2-ol fed flies. Ethanol/acetaldehyde $(\mathbf{)})$ and propan-2-ol/acetone $(O)$ ratios at the times indicated.

the external medium and in the flies. Samples were taken at 2, 8, 24, 48, 72, 96 and 192 hours and treated as described in Material and Methods. $\mathrm{ADH}$ and AKR activities and ethanol-acetaldehyde concentrations are given in fig. 3 for ethanol treated flies and the same enzyme activities and propan-2-ol-acetone concentrations for propan-2-ol treated flies are given in fig. 4 .

\section{Recovery of $A D H$ activity after propan-2-ol treatment}

$\mathrm{ADH}$ activity rises when adult flies of $D$. hydei are treated for 48 hours with 1 per cent $(\mathrm{v} / \mathrm{v})$ ethanol supplemented medium (fig. 3) but decreases dramatically when they are reared during the same time on food supplemented with 0.5 per cent $(v / v)$ propan-2-ol (fig. 4). It has been claimed that this decrease of activity observed in the case of propan2-ol was due to a change in the relative proportion of the multiple forms of $\mathrm{ADH}$ favoured in the presence of a variety of carbonyl compounds (Papel et al., 1979) and this in fact has been reported in several Drosophila species (Vilageliu and Gonzàlez-Duarte, 1980; Van Delden, 1982). It is also known that propan-2-ol treated flies would recover normal levels of enzyme activity when transferred to the usual medium. The same hap- 

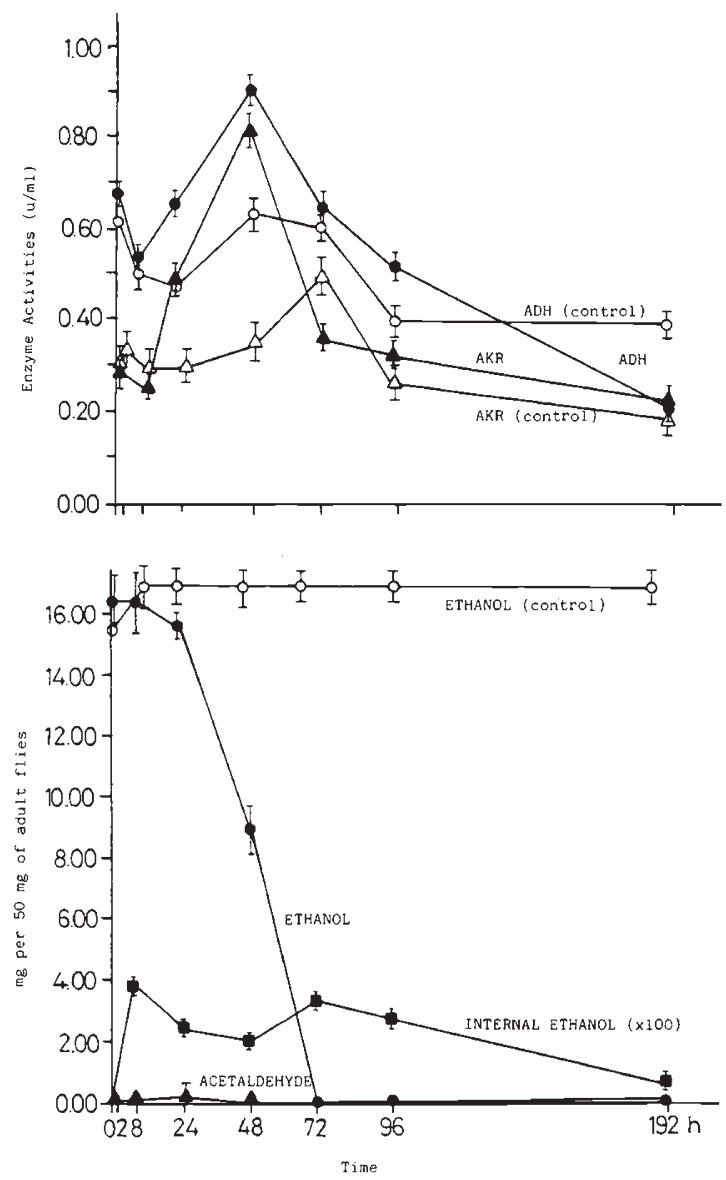

Figure 3 Above. ADH and AKR activities and ethanol and acetaldehyde concentrations in 1 per cent $(v / v)$ ethanol fed flies. ADH (O) and AKR ( $\mathbf{\Delta})$ activities in $D$. hydei adults fed on 3 per cent $(w / v)$ sucrose solution supplemented with 1 per cent $(\mathrm{v} / \mathrm{v})$ ethanol for the times indicated. $\operatorname{ADH}(O)$ and AKR $(\triangle)$ activities in adult flies fed on sucrose solution without ethanol. Enzyme activities are expressed in $\mathrm{u} / \mathrm{ml} \pm$ S.E.M.

Below. The concentrations of ethanol (O) and acetaldehyde $(\boldsymbol{\Delta})$ in the external medium of ethanol treated flies, internal ethanol $(\mathbf{a}) \times 100$. Ethanol $(O)$ concentration in control vials without adult flies. Internal concentrations are expressed in $\mathrm{mg}$ per $50 \mathrm{mg}$ of adult flies. Ethanol and acetaldehyde in the external medium and ethanol in control vials is expressed in $\mathrm{mg} \pm$ S.E.M.

pens when acetone treatment is stopped; normal ADH activity is regained after 8-9 days (Papel et al., 1979).

On the other hand it has been reported that cycloheximide is a potent inhibitor of protein synthesis in Drosophila. Flies reared on sucrose solution containing 0.5 per cent $(\mathrm{w} / \mathrm{v})$ cycloheximide decrease their protein synthesis to $10-20$ per cent of the normal value and if fed continuously with this compound the level decreases to 10 per
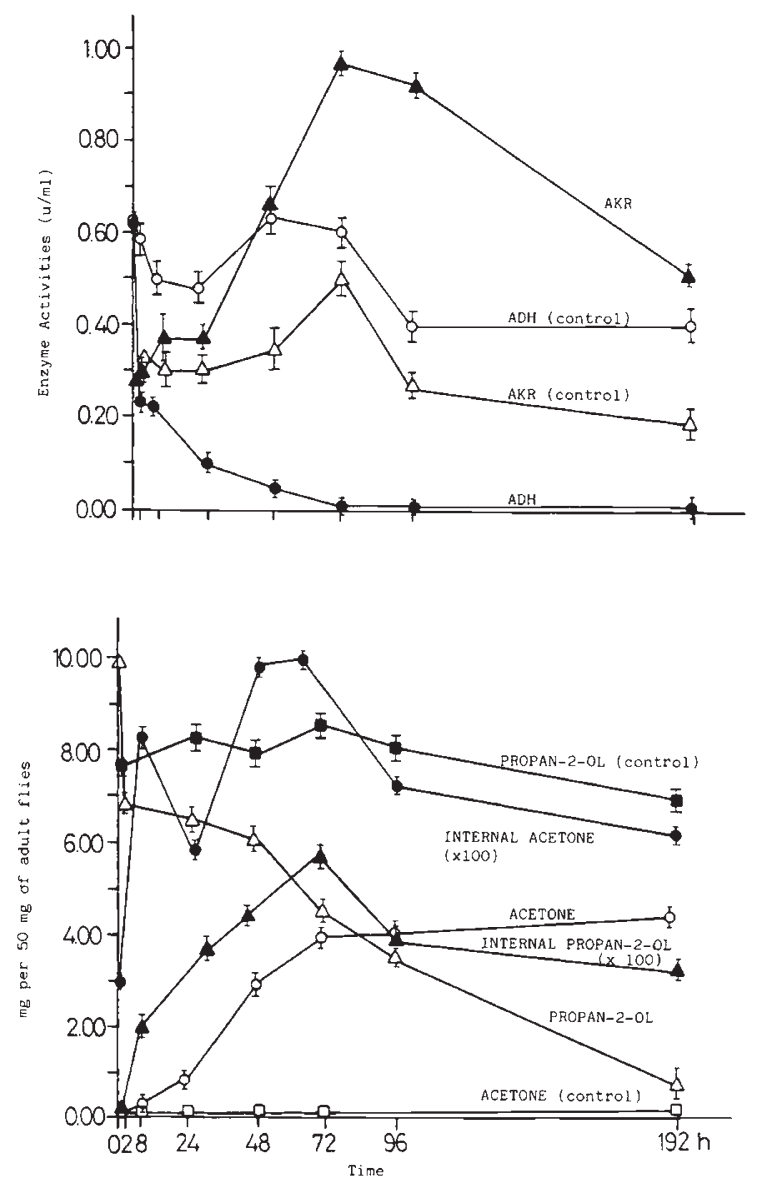

Figure 4 Above. ADH and AKR activities and propan-2-ol and acetone concentration in 0.5 per cent $(v / v)$ propan-2-ol treated flies. ADH $(\boldsymbol{O})$ and $\operatorname{AKR}(\boldsymbol{\Delta})$ activities in adults fed on 3 per cent $(w / v)$ sucrose solution supplemented with 0.5 per cent (v/v) propan-2-ol. ADH (O) and AKR $(\triangle)$ activities in adult flies fed on sucrose solution without propan-2-ol. Enzyme activities are expressed in $\mathrm{u} / \mathrm{ml} \pm$ S.E.M.

Below. Acetone $(\boldsymbol{O})$ and propan-2-ol $(\Delta)$ concentrations in the internal medium $(\times 100)$; acetone $(O)$ and propan-2. ol $(\triangle)$ in the external medium. Propan-2-ol (ם) and acetone $(\square)$ in control vials without adult flies. Internal concentrations are expressed in mg per $50 \mathrm{mg}$ of adult flies. Propan-2ol and acetone in the external medium and in control vials is expressed in $\mathrm{mg} \pm$ S.E.M.

cent (Dingley and Maynard-Smith, 1968). All these data led us to plan another experiment to determine if the increase in $\mathrm{ADH}$ activity was due to a) reactivation of pre-existing enzyme molecules or b) new synthesis of enzyme. If the second hypothesis was correct cycloheximide would severely affect the recovery of enzyme activity.

To test whether cycloheximide by itself at 0.5 per cent $(w / v)$ affected ADH activity the following experiment was devised. Groups of 20 adults of 
D. hydei were kept in vials with 3 per cent $(\mathrm{w} / \mathrm{v})$ sucrose solution supplemented with 0.5 per cent $(\mathrm{w} / \mathrm{v})$ cycloheximide. Control vials had 3 per cent $(\mathrm{w} / \mathrm{v})$ sucrose solution. Samples were taken at 24 , 48 and 72 hours to determine ADH activity. In all cases cycloheximide fed flies showed the same level of ADH activity than non-treated flies.

For this experiment groups of 20 adults of $D$. hydei that had been maintained for 24 hours on a medium containing 1 per cent $(v / v)$ ethanol or 0.5 per cent $(\mathrm{v} / \mathrm{v})$ propan-2-ol were transferred to vials containing sucrose and cycloheximide administered as previously described. Control vials without cycloheximide were also set. Samples were taken after 24 hours of treatment up to 96 hours and $\mathrm{ADH}$ activity was determined. The results are shown in fig. 5 .

\section{DISCUSSION}

The importance of ADH in alcohol metabolism in Drosophila is well known. This enzyme catalyses the first step in alcohol metabolism by the oxidation of alcohols to aldehydes and ketones. Presumably, other enzymes also participate in other steps of this metabolic pathway. Although much less

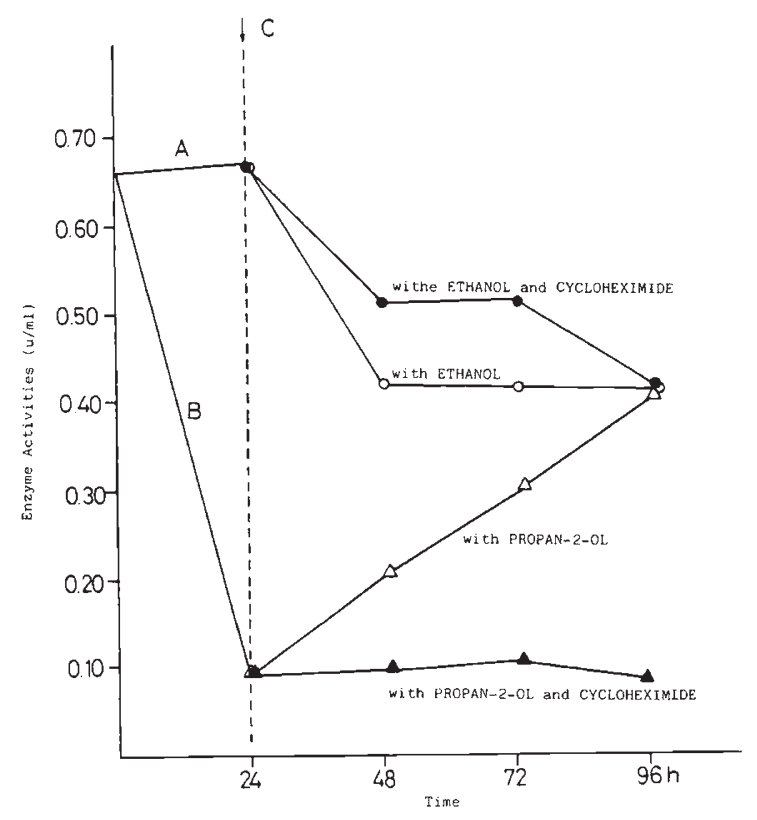

Figure 5 Cycloheximide treatment. ADH activity of 1 per cent $(\mathrm{v} / \mathrm{v})$ ethanol (A) and 0.5 per cent $(\mathrm{v} / \mathrm{v})$ propan-2-ol (B) treated flies for 24 hours. After this time adults were transferred (C) to a 3 per cent $(w / v)$ sucrose solution supplemented with 0.5 per cent $(w / v)$ cycloheximide $(\boldsymbol{O}, \boldsymbol{\Delta})$ and without cycloheximide $(O, \triangle)$. ADH activity has been determined at the times indicated and is given in $\mathrm{u} / \mathrm{ml}$. is known concerning the transformation of aldehydes, an ketones and aldo-keto reductase activity in $D$. hydei has been detected (Atrian and Gonzàlez-Duarte, 1985). This enzyme can use acetaldehyde and acetone as substrates and could be homologous to a NADPH-dependent aldehyde reductase reported in different animal species including $D$. melanogaster (Davidson et al., 1978). Our results show that $\mathrm{ADH}$ and $\mathrm{AKR}$ react differently towards propan-2-ol ingestion probably reflecting their different role in alcohol metabolism. Propan-2-ol treatment causes a marked decrease of ADH activity and a clear increase of AKR activity (fig. 4). Differences are also observed in the relationships substrate/product attained with ethanol and propan-2-ol (fig. 2). These differences probably reflect the rapid transformation of acetaldehyde in the fly whereas acetone is eliminated unchanged, appearing in the external medium.

When 1 per cent $(v / v)$ ethanol is added to the medium ADH and AKR activities rise sharply in the first 48 hours decreasing progressively afterwards until the end of the experiment. As fig. 3 shows, both enzymes have comparable behaviour. When compared with control flies fed with no ethanol, it appears that ethanol produces a higher increase of $\mathrm{ADH}$ and AKR activities than unsupplemented medium. It has been reported that $2 \cdot 5$ per cent $(\mathrm{v} / \mathrm{v})$ ethanol induced an ADH activity $2 \cdot 5$-fold higher than in larvae of $D$. melanogaster fed on unsupplemented sucrose diet (McKechnie and Geer, 1984). Larvae of $D$. funebris and $D$. melanogaster show the same effect (GonzàlezDuarte and Vilageliu, 1984). And because of the apparent nutritional importance of ethanol to Drosophila it is not surprising that adults of $D$.hydei also react to dietary ethanol concentration. Ethanol induces a moderate increase of AKR activity, 24 hour before that in control flies. Fig. 3 also shows the evolution of ethanol and acetaldehyde concentrations in the external and internal medium during the experiment. Ethanol concentration rises in the flies at the same time as it decreases in the external medium. So, ethanol is ingested and eventually metabolised in the flies. Acetaldehyde concentration is very low; it is a highly toxic compound to the flies and only an extremely low concentration could be tolerated without being lethal. The concentration of acetaldehyde that appears in the external medium cannot be easily explained at present; neither can the maximum value attained after 24 hours.

Propan-2-ol treatment is shown in fig. 4. In this case ADH and AKR show clearly an opposite 
behaviour in propan-2-ol fed adults although they are quite similar in flies fed on unsupplemented diet. AKR activity is induced by approximately threefold, but ADH activity is almost undetectable after 72 hours. That propan-2-ol induces a marked decrease of $\mathrm{ADH}$ activity has been reported by various authors in different species of Drosophila: D. buzzatii (Fontdevila et al., 1980), D. melanogaster, $D$. funebris and $D$. immigrans (Vilageliu and Gonzàlez-Duarte, 1980; Papel et al., 1979). The toxicity of propan-2-ol and acetone have also been studied (David et al., 1981). The increase in the activity of AKR seems to strengthen the argument for its involvement in the alcohol metabolism of Drosophila. The propan-2-ol and acetone concentration in the flies show an increase of both compounds during the first 72 hours. During this time acetone concentration does not show a continuous increase and possibly is again partially transformed to propan-2-ol due to AKR activity.

This effect has also been observed in larvae of D. melanogaster, D. funebris and D. immigrans grown in the presence of propan-2-ol (Vilageliu and Gonzàlez-Duarte, 1980; Gonzàlez-Duarte and Vilageliu, 1984). Acetone concentration in these flies also reaches much higher values than propan2-ol (David et al., 1981). The highest levels of acetone ( 72 hours) correspond exactly with maximum values of AKR activity and minimum values of $\mathrm{ADH}$ activity. When considering the external medium there is one point of importance: acetone concentration rises progressively. It seems that the acetone cannot be further metabolised in the flies, and has to be eliminated unchanged.

Our data suggest that cycloheximide treatment does not affect ADH activity in ethanol fed flies (fig. 5), but the recovery of ADH activity is severely impaired in flies treated with propan-2-ol, suggesting that new synthesis of enzyme is responsible for this recovery, rather than interconversion of the different molecular forms or reactivation of preexisting molecules. In the absence of cycloheximide the level of recovery attained is just the same as that of ethanol treated flies where ADH activity had not been reduced. This seems to indicate that $\mathrm{ADH}$, at least under these experimental conditions, is subjected to stringent controls that regulate its level of activity.

Acknowledgements We would like to thank Dr A. Prevosti for continual support and Drs E. Juan and LL. Vilageliu for helpful suggestions during the course of this study. This research was supported by CAYCIT grants no. 0821-81 and 3346-83.

\section{REFERENCES}

ATRIAN, S. AND GONZÀlEZ-DUARTE, R. 1985. An aldo-keto reductase activity in Drosophila melanogaster and Drosophila hydei: A possible function in alcohol metabolism. Comp. Biochem. Physiol, 81B, 949-952.

DAVID, J., VAN HERREWEGE, J., MONCLUS, M. AND PREVOSTI, A. 1979. High ethanol tolerance in two distantly related Drosophila species: A probable case of recent convergent adaptation. Comp. Biochem. Physiol. 63C, 53-56.

DAVID, J., VAN HERREWEGE, J., SCHEEMAEKER-LOUIS, M. AND PLA, E. 1981. Drosophila alcohol dehydrogenase: detoxification of isopropanol and acetone, substances not used in energy metabolism. Heredity, 47, 263-268.

DAVIDSON, W. S., WALTON, D. J. AND FLYNN, T. G. 1978. A comparative study of the tissue and species distribution of NADPH-dependent aldehyde reductase. Comp. Biochem. Physiol., 60B, 309-315.

DINGLEY, F. AND MAYNARD SMITH, J. 1968. Temperature acclimatization in the absence of protein synthesis in Drosophila subobscura. J. Insect Physiol., 14, 1185-1194.

FONTDEVILA, A., SANTOS, M. AND GONZÀlEZ-DUARTE, R. 1980. Genotype-isopropanol interaction in the Adh locus of $D$. buzzatii. Experientia, 36, 398-400.

GONZÀLEZ-DUARTE, R. AND VILAGELIU, LL. 1984. Metabolic response to ethanol and isopropanol in $D$. funebris and D. immigrans. Comp. Biochem. Physiol., 80C, 189-193.

JENTZSCH, D., KRUGER, U. AND LEBRECHT, G. 1967. In Angewondte gas chromatographie. Badenseewerk. PerkinElmer.

JUAN, E. AND GONZÀleZ-DUARTE, R. 1980. Purification and enzyme stability of alcohol dehydrogenase from Drosophila simulans, Drosophila virilis and Drosophila melanogaster

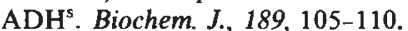

MCKECHNIE, S. E. AND MORGAN, P. 1982. Alcohol dehydrogenase polymorphism of $D$. melanogaster: Aspects of alcohol and temperature variation in the larval environment. Austr. J. Biol. Sci. 35, 85-93.

MCKECHNIE, S. W. AND GEER, B. W. 1984. Regulation of alcohol dehydrogenase in Drosophila melanogaster by dietary alcohol and carbohydrate. Insect Biochem. 14(2); 231-242.

PAPEL, I., HENDERSON, M., VAN HERREWEGE, J., DAVID, J. AND SOFER, W. 1979. Drosophila alcohol dehydrogenase activity in vitro and in vivo: Effects of acetone feeding. Biochem. Genet. 17 (5/6); 553-563.

TURNER, A. J., AND TIPTON, K. F. 1972. The characterization of two reduced nicotinamide-adenine dinucleotide phosphate-linked aldehyde reductases from pig brain. Biochem. J. 130, 765-772.

VAN DELDEN, w. 1982. The alcohol dehydrogenase polymorphism in Drosophila melanogaster. In Evolutionary Biology (Hecht, K. K., Wallace, B. \& Prance, G. T., eds) Vol. 15 pp 187-222. Plenum Press. New York and London.

VIGUE, C. L. AND JOHNSON, F. M. 1973. Isozyme variability in species of the genus Drosophila. VI Frequency-propertyenvironments relationships of allelic alcohol dehydrogenase in D. melanogaster. Biochem. Genet. 9, 213-227.

VILAGELIU, LL. AND GONZÀLEZ-DUARTE, R. 1980. Effect of ethanol and isopropanol on the activity of alcohol dehydrogenase, viability and life-span in Drosophila melanogaster and Drosophila funebris. Experientia, 36, 828829.

VILAGELIU, LL. AND GONZÀlEZ-DUARTE, R. 1984. Alcohol dehydrogenase from Drosophila funebris and Drosophila immigrans: Molecular and evolutionary aspects. Biochem. Genet. 22, 797-815. 